\title{
Correction to: Application of GIS and AHP Method in Forest Fire Risk Zone Mapping: a Study of the Parambikulam Tiger Reserve, Kerala, India
}

\author{
S. Nikhil ${ }^{1} \cdot$ Jean Homian Danumah ${ }^{2} \cdot$ Sunil Saha $^{3} \cdot$ Megha K. Prasad $^{4} \cdot$ A. Rajaneesh ${ }^{5} \cdot$ Pratheesh C. Mammen $^{1} \cdot$ \\ R. S. Ajin ${ }^{1}$ (D) $\cdot$ Sekhar L. Kuriakose ${ }^{1}$
}

Published online: 17 May 2021

(C) Springer Nature Switzerland AG 2021

\section{Correction to: Journal of Geovisualization and Spatial Analysis https://doi.org/10.1007/s41651-021-00082-x}

In the original article the reference "Gigović L, Pourghasemi HR, Drobnjak S, Bai S (2019) Testing a new ensemble model based on SVM and random forest in forest fire susceptibility assessment and its mapping in Serbia's Tara National Park. Forests 10(5). https://doi.org/10.3390/f10050408" was listed out of alphabetical sequence.

Publisher's Note Springer Nature remains neutral with regard to jurisdictional claims in published maps and institutional affiliations.

The online version of the original article can be found at https://oi.org/ 10.1007/s41651-021-00082-x

\section{R. S. Ajin}

ajinares@ieee.org; ajinares@gmail.com

1 Kerala State Emergency Operations Centre (KSEOC), Kerala State Disaster Management Authority (KSDMA),

Thiruvananthapuram, Kerala, India

2 Centre Universitaire de Recherche et d'Application en Télédétection (CURAT), Université Félix Houphouët-Boigny, Abidjan, Côte d'Ivoire

3 Department of Geography, University of Gour Banga, Malda, West Bengal, India

4 Department of Remote Sensing, Bharathidasan University, Tiruchirappalli, Tamil Nadu, India

5 Department of Geology, University of Kerala, Thiruvananthapuram, Kerala, India 